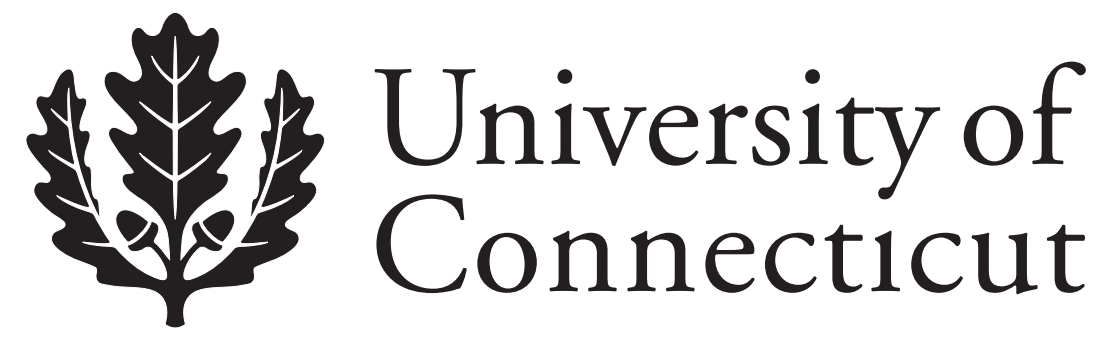

Department of Economics Working Paper Series

Judicial versus "Natural" Selection of Legal Rules with an Application to Accident Law

Thomas J. Miceli

University of Connecticut

Working Paper 2010-27

November 2010

341 Mansfield Road, Unit 1063

Storrs, CT 06269-1063

Phone: (860) 486-3022

Fax: (860) 486-4463

http://www.econ.uconn.edu/

This working paper is indexed on RePEc, http://repec.org/ 


\begin{abstract}
Law and economics scholars argue that the common law evolves toward efficiency. Invisible hand theories suggest that the law is primarily driven by a selection process whereby inefficient laws are litigated more frequently than efficient laws, and hence are more likely to be overturned. But the preferences of judges also necessarily affect legal change. This paper models the interaction of these two forces to evaluate the efficiency claim, and then applies the conclusions to the evolution of accident law in the U.S. Specifically, it attributes the persistence of negligence to its efficiency properties, despite its having been initially selected by judges for a different reason.
\end{abstract}

Journal of Economic Literature Classification: B52, K13, K41

Keywords: Accident law, legal change, judicial decision-making, natural selection 


\section{Judicial versus "Natural" Selection of Legal Rules with an Application to Accident Law}

\section{Introduction}

The common law consists of the body of legal rules (or precedents) that arise as a result of judicial resolution of lawsuits filed by private parties seeking legal redress for harm inflicted by other parties. For example, victims of accidents seek compensation for damages caused by an injurer's actions, and the rules of tort (accident) law describe the conditions under which such compensation is due. The common law changes over time, but unlike legislation, it is not driven by interest group politics or by the desire of courts to address pressing policy questions. Rather, it can only respond to those particular disputes that come before judges to be adjudicated. Even the Supreme Court, which has the ability to decide which cases not to review, cannot determine the population of cases from which it must choose.

It has nevertheless been one of the central theses of the law and economics movement that the common law has a tendency to evolve in the direction of efficiency. Initially, this claim was based on Posner's argument that because judges "cannot do much... to alter the slice of the pie that the various groups in society receive, they might as well concentrate on increasing its size" (Posner, 2003, p. 252). According to this perspective, the law evolves toward efficiency because judges actively pursue that goal; in other words, the law is judge-driven. Of course, if judicial preference is the predominant force driving the law, then it will clearly not evolve toward efficiency if judges systematically pursue other goals. ${ }^{1}$

In response to this problem, economists have proposed another mechanism by which the law will tend to evolve toward efficiency without the conscious help of judges. This theory, first

\footnotetext{
${ }^{1}$ Hadfield (1992) argues that even if judges are efficiency-seeking, they lack the information to formulate efficient rules.
} 
proposed by Rubin (1977) and Priest $(1977),{ }^{2}$ relies on the nature of the common law process and its tendency to produce a kind of natural selection in favor of efficient laws. The basic argument underlying these "invisible hand" theories is that inefficient laws will be litigated more frequently than efficient laws because they impose larger costs on victims. Thus, inefficient laws will come before the court for re-examination more frequently than efficient laws, resulting in a higher probability that the inefficient laws will be overturned, provided, of course, that judges are not biased against efficiency. The result of this "selective litigation effect" is therefore a general trend toward efficiency.

Cooter and Kornhauser (1980) formally examined this claim using a Markov model of legal evolution under the assumption that judges are completely unbiased. Their results showed that, although this process will not completely rid the common law of inefficient rules in a steady-state equilibrium (except under special conditions), the selective litigation effect will tend to increase the proportion of efficient laws. The model to be developed in the next section uses a simplified version of the Cooter and Kornhauser framework to examine the interaction between judicial bias and selective litigation in directing legal change. ${ }^{3}$ Subsequent sections then apply the conclusions to the evolution of accident law in the United States, beginning in the nineteenth century.

\section{Theoretical Analysis}

I consider the simplest possible setting in which there are only two possible legal rules, indexed by $i=1,2$. Let the probability that rule $i$ will be litigated over some fixed time interval be given by $a_{i}$. This represents the probability that rule $i$ will be challenged in court by a victim

\footnotetext{
${ }^{2}$ Also see Landes (1971), Goodman (1978), Terrebonne (1981), and Gennaioli and Shleifer (2007a,b).

${ }^{3}$ For more detailed analysis of this hybrid model, see Miceli $(2009,2010)$.
} 
(plaintiff) during this time, thus giving a judge the opportunity to overturn it. As discussed above, this can only happen if disputes arise under rule $i$ such that plaintiffs find it in their interest to go to court. In the context of accident law, for example, this means that a victim of an accident files suit under rule $i$ in hopes of recovering monetary compensation for his or her losses. I assume that the probability of litigation for both rules is strictly positive; that is, $a_{1}>0$ and $a_{2}>0$. (Obviously, if $a_{i}=0$ over some time interval, then rule $i$ cannot be replaced.)

The behavior (bias) of judges is captured by the parameter $p_{i j}$, which is defined to be the probability that a judge will replace rule $i$ with rule $j, i, j=1,2$. Thus, if a judge confronts a case involving rule $1, p_{12}$ is the probability that he or she will replace it with rule 2 , and $1-p_{12}$ is the probability that he or she will uphold rule 1. Likewise, if a judge confronts a case involving rule $2, p_{21}$ is the probability that he or she will replace it with rule 1 , and $1-p_{21}$ is the probability he or she will uphold rule 2. ${ }^{4}$ The assumption that the law evolves according to a Markov process implies that the $p_{i j}$ 's are constant over time.

Let us now suppose that the initial distribution of legal rules is given by $x=\left\{x_{1}, x_{2}\right\}$, where $x_{1}$ is the proportion of rule 1 and $x_{2}=1-x_{1}$ is the proportion of rule 2 . Then, after one period where the law evolves according to the above process, a new distribution, $y=\left\{y_{1}, y_{2}\right\}$ (where $y_{2}=1-$ $\left.y_{1}\right)$ is in place. Thus, for rule 1 we have

$$
y_{1}=x_{1}\left(1-a_{1}\right)+x_{1} a_{1}\left(1-p_{12}\right)+\left(1-x_{1}\right) a_{2} p_{21},
$$

where the three terms on the right-hand side correspond to the three ways that rule 1 can emerge in the second period. The first is when no case involving rule 1 comes before the court during the fixed time interval, which means that the percentage of rule 1 remains $x_{1}$; the second is when a case involving rule 1 occurs and the judge upholds the rule; and the third is when a case

\footnotetext{
${ }^{4}$ Thus, in our simple model, $p_{11} \equiv 1-p_{12}$ and $p_{22} \equiv 1-p_{21}$.
} 
involving rule 2 occurs and the judge overturns the rule (i.e., replaces it with rule 1). A similar expression exists for rule 2 .

The steady-state equilibrium proportion of rule 1 , denoted $s_{1}$, can be found by setting $x_{1}=y_{1}=s_{1}$ in (1) and solving for $s_{1}$ to obtain

$$
s_{1}=\frac{a_{2} p_{21}}{a_{2} p_{21}+a_{1} p_{12}} .
$$

Similarly, the steady-state proportion of rule 2 is ${ }^{5}$

$$
s_{2}=\frac{a_{1} p_{12}}{a_{2} p_{21}+a_{1} p_{12}} .
$$

These expressions reflect the combined effects of judicial bias (as embodied by the $p_{i j}$ 's) and selective litigation (as embodied by the $a_{i}$ 's) in determining the equilibrium proportions of the two rules. We now examine how each of these two factors affects the direction of legal change.

Consider first the effect of judicial bias. Suppose, for example, that all judges are biased in favor of rule 1 . That is, $p_{21}=1$ and $p_{12}=0$, or, judges confronted with a case involving rule 2 will overturn it and replace it with rule 1, but they will uphold rule 1 . It follows immediately from (2) and (3) that $s_{1}=1$ and $s_{2}=0$. Thus, judicial bias will eventually cause the law to evolve completely toward the favored rule, regardless of the relative litigation rates of the two rules. If judges are efficiency-seeking, as Posner contends, then this will eventually produce an efficient common law, but it could also work against efficiency if judges pursue other goals (as will be suggested below).

Now consider the effect of selective litigation. To do so, suppose that judges are completely unbiased; that is, $p_{12}=p_{21}=1 / 2$. Then, (2) and (3) reduce to

$$
\begin{aligned}
& s_{1}=\frac{a_{2}}{a_{1}+a_{2}} \\
& s_{2}=\frac{a_{1}}{a_{1}+a_{2}} .
\end{aligned}
$$

\footnotetext{
${ }^{5}$ Note that, as required, $s_{1}=1-s_{2}$.
} 
Thus, both rules remain in the population as long as there is some positive probability that each will be litigated. The equilibrium proportions will differ, however, depending on the relative litigation rates. In particular, observe that $s_{i}>s_{j}$ as $a_{i}<a_{j}, i, j=1,2, i \neq j$. That is, the rule with the lower litigation rate will predominate in the population. Further, as the litigation rate for rule $i$ falls, the greater will be its proportion in the population. This reflects the pure selection effectthe less often a rule is litigated, the smaller is the chance that it can be replace by another rule. In the limit, if a rule is never litigated it cannot be replaced.

In the general steady state as reflected by (2) and (3), the distribution of legal depends on the combined effects of judicial bias and selective litigation. Thus, even biased judges are constrained by the type of cases that come before them, which limits their ability to shape the law. Another factor limiting judicial bias is the strength of precedent. In some cases, precedent completely binds judges to past rules, thus preventing them from changing the law. However, precedent is rarely completely binding, especially if it has not persisted for a long time (Landes and Posner, 1976). ${ }^{6}$ In that case, one can show that precedent will not affect the direction of legal change, only the speed at which it will occur (Miceli, 2009). ${ }^{7}$ Intuitively, as long as there is a positive probability that judges will overturn precedent, the evolutionary forces described above, and in particular, the steady state distribution of legal rules, will not be affected. This claim is formally proved in Appendix 1.

\section{Application of the Model to Accident Law in the U.S.}

This section applies the above model to the development of accident law in the United States, beginning in the nineteenth century. The predominant common law rule governing the

\footnotetext{
${ }^{6}$ Also see Miceli and Cosgel (1994) and Gennaioli and Shleifer (2007a), who examine the factors that affect a judge's decision of whether or not to overturn a precedent.

${ }^{7}$ See Appendix 1 for a formal demonstration.
} 
assignment of liability for unintentional accidents since that time has been negligence (Posner, 1972, p. 29), which imposes on parties engaged in risky activities a duty to take reasonable care to avoid accidents. Failure to meet the due standard subjects a party to the threat of liability for any damages that his or her negligence may have caused. In contrast, an injurer who meets (or exceeds) the due standard avoids any liability.

Negligence only emerged as a separate component of tort law, however, during the early to mid- nineteenth century. ${ }^{8}$ Prior to that time, claims for negligence were limited to certain "public" callings, such as common carriers, innkeepers, blacksmiths, or surgeons, who were contractually obligated to provide proper service, the breach of which subjected them to liability; or to sheriffs, who were held negligent when they allowed debtors to escape custody. In none of these areas, however, did negligence carry the modern meaning of a failure to take due carerather, it connoted "nonfeasance;" that is, failure to perform a pre-existing, usually contractual, duty (Horowitz, 1992a, pp. 86-87). The broader realm of accident law—so-called accidents between "strangers"-was governed by strict liability, which subjected unintentional injurers to liability for any accidents that they caused. The rise of the modern concept of negligence, meaning the failure to take due care (i.e., to be "at fault"), coincided with the onset of the industrial revolution and the consequent explosion of accidents caused by machinery and railroads.

Given this account, we are interested in why negligence emerged at that time, and also why it has persisted in most areas of tort law up to the present day. The following sections address these questions in light of the above model of legal change.

\subsection{The Emergence of Negligence: The Horowitz Hypothesis}

\footnotetext{
${ }^{8}$ See, generally, Keeton, et al. (1984, pp. 160-161) and Horowitz (1992a, pp. 85-99).
} 
Perhaps the most famous account of the rise of negligence in the nineteenth century is attributable to Morton Horowitz (1992a), who argued that judges consciously adopted the rule as a way to subsidize economic growth, especially the railroads, at the onset of the industrial revolution. ${ }^{9}$ By replacing strict liability with negligence, the argument goes, judges allowed business enterprises to avoid liability for accidents as long as they took reasonable care to avoid them. Businesses thereby received an implicit subsidy at the expense of accident victims. The key element of this hypothesis for our purposes is that this change was driven by judges. Prior to the nineteenth century, judges essentially viewed the common law as a fixed and static set of doctrines that were not meant to serve policy ends. Predictability of the law was paramount. However, "[a]s judges began to conceive of common law adjudication as a process of making and not merely discovering legal rules, they were led to frame general doctrines based on a self-conscious consideration of social and economic policies" (Horowtiz, 1992a, p. 2). In the area of accident law, that end was promotion of economic development, and the means by which judges sought to achieve it was by limiting the exposure of firms to liability for damages that arose as part of the normal course of business. To be sure, businesses were still responsible for taking reasonable precautions to avoid accidents, and they were held liable for any accidents that their failure to do so caused, but the innovation of the negligence rule was to absolve them of liability for those accidents that inevitably occurred even when they were exercising reasonable care. As a result, "[a]fter 1840 the principle that one could not be held liable for socially useful activity exercised with due care became a commonplace of American law" (Horowitz, 1992a, p. 99). ${ }^{10}$

\footnotetext{
${ }^{9}$ See especially Chapter III of Horowitz (1992a).

${ }^{10}$ Oliver Wendell Holmes, in his classic treatise on the common law (1963 [1881]), provided the intellectual basis for this change, principally by arguing for an objective standard of negligence (Horwitz, 1992b, p. 124).
} 
The Horowitz Hypothesis clearly reflects a view that tort law evolved in the nineteenth century predominantly as a result of judicial bias rather than selective litigation. As the model showed, although the selection effect and precedent operate as limiting factors on the ability of judges to shape the law, if the bias of judges is strong enough, it will eventually predominate, yielding a corner solution in which the favored rule prevails. This story seems to describe rather well the development of accident law during the nineteenth century, and the eventual triumph of the negligence rule. ${ }^{11}$

Even if one accepts Horowitz hypothesis as an explanation for the emergence and eventual predominance of negligence law in the nineteenth century, however, it seems implausible to argue that common law judges have continued to promote negligence as a way to subsidize business. As Posner (1972, p. 29) notes, "any occasion for subsidization has long passed." If anything, the balance of interests has swung toward accident victims, and in the area of products liability, at least, the law has correspondingly swung back toward strict liability (Epstein, 1980; Landes and Posner, 1985). ${ }^{12}$ Most other areas of accident law, however, continue to be governed by negligence principles. The question is why this is so. In the absence of systematic judicial bias in favor of negligence, the above model of legal change implies that selective litigation should have become the dominant force. The next section posits why this has resulted in the persistence of negligence.

\subsection{The Persistence of Negligence: Posner and Hand}

\footnotetext{
${ }^{11}$ But see Posner (1972, p. 30), who suggests that a negligence rule may not have subsidized industry because, as long as businesses were encouraged by the rule to invest in optimal safety, the they had to fully bear the cost. What Posner ignores, however, is that, because injurers are absolved of liability, they may overinvest in the activity itself, even though they do so in a "safe" way. For example, a railroad may run more than the efficient number of trains, even though each train is equipped with all necessary safety devices. In contrast, strict liability will result in the efficient activity level because businesses will internalize the full damages that they cause and will thus choose both the efficient safety and activity levels. (See, for example, Shavell (2004, pp. 196-199).) Posner (2003, p. 254-255) later recognized this point.

${ }^{12}$ Some have argued that the trend toward strict liability in products liability in fact reflects an anti-efficiency bias (Priest, 1988; Viscusi, 1991).
} 
As noted above, theories of legal change based purely on selective litigation (invisible hand theories) assert that the law will evolve toward efficiency because inefficient laws will tend to be litigated more frequently than efficient laws, thus allowing them to be weeded out of the population. Although the model showed that this process will not generally result in complete dominance by any one rule, the less-litigated (i.e., more efficient) rule will increase proportionately in number (see equations (4) and (5)). The persistence of negligence in the absence of judicial bias therefore makes sense in this context if it is in fact an efficient rule for allocating accident costs.

Posner (1972) was the first to argue that negligence is more efficient than strict liability in the sense that it results in lower accident costs. The basis for his argument is the formalization of the ordinary care standard famously offered by Judge Learned Hand in the case of U.S. v. Carroll Towing Co. ${ }^{13}$ According to the so-called "Hand test," the determination of negligence is based on three factors: the probability that an accident will occur $(P)$, the damages, or loss, in the event of an accident $(L)$, and the burden of precautions necessary to prevent the accident $(B)$. If the burden is less than the expected damages, or $B<P L$, then a defendant who failed to take the necessary precautions should be held negligent, whereas if the reverse is true, or $B>P L$, then the defendant should not be held negligent. As it turns out, this standard, properly interpreted, ${ }^{14}$ creates exactly the right incentives for injurers to invest in efficient accident avoidance.

Suppose, for example, than an injurer can avoid an accident by spending $\$ 100$ on some safety measure or by otherwise being careful, whereas if he does not invest, there is a one in four chance of an accident that would cause damages of $\$ 500$ to the victim. Is it efficient for the injurer to invest in the safety measure? The answer is yes since, by spending $\$ 100$, he can avoid

\footnotetext{
13 159 F.2d 169 (2d. Cir. 1947).

${ }^{14}$ Specifically, the $P$ must be interpreted as the probability that an accident would occur if the precaution in question were not taken. In other words, it is the amount that the precaution reduces the probability of an accident.
} 
an expected cost of $\$ 125(=.25 \times \$ 500)$. If, in contrast, the damage from an accident is only, say, $\$ 300$, but everything else is the same, then it would not be efficient for the injurer to invest the $\$ 100$ because by doing so he would only save $\$ 75(=.25 \times \$ 300)$ in expected costs. The point is that in situations where some accident risk is inevitable, either the cost of accident prevention, or the cost of accidents, must be incurred, and efficiency dictates that it should be the lesser of the two costs. Some accidents are therefore "efficient" in the sense that the cost of preventing them is higher than the expected loss.

Now consider how the Hand test for negligence creates an incentive for injurers to make efficient safety decisions. Suppose initially that the above precaution is efficient (that is, the loss from an accident is $\$ 500$ ). Since $B<P L$ in this case, the court will find an injurer negligent if he failed to invest in the safety measure and an accident occurs. The expected liability for the injurer at the time he must make his decision is therefore $\$ 125$. The injurer knows, however, that by spending the $\$ 100$ on accident prevention, he can avoid any future liability. Thus, he will clearly invest in precaution because by spending $\$ 100$ he avoids an expected cost of $\$ 125$.

Now suppose that accident prevention is not efficient (i.e., the loss from an accident is only $\$ 300$ ). Since $B>P L$ in this case, the court will not find the injurer negligent if he failed to take care and an accident occurs. He therefore has no incentive to invest the $\$ 100$ in accident prevention because he gets no benefit from doing so. Again, he makes the efficient choice. It is easy to show that the efficiency of the Hand test extends to more general settings where precaution is continuous and there is some residual risk of an accident when the injurer invests in efficient accident precaution.

The preceding argument has shown that a negligence rule creates efficient incentives for injurers regarding accident prevention. It does this by creating a threshold of behavior-due 
care - that shields injurers from liability if they meet that standard. Injurers thus have a strong incentive to do so. Of course, strict liability also induces injurers to invest in efficient accident prevention, but it does so by imposing on them the full liability for any accident losses that they cause. Injurers therefore cannot escape liability by taking efficient (ordinary) care, but they still have an incentive to do so in order to minimize their overall exposure to accident costs (prevention plus liability).

The argument to this point has established that negligence and strict liability are equally effective in regard to efficient injurer precaution, but the claim above was that negligence is superior to strict liability in terms of minimizing accident costs. To establish this, it is necessary to introduce the role of victim precaution. In many accident settings, victim care is at least as important as injurer care in reducing accident risk. For example, drivers should stop and look both ways at railroad crossings, and consumers of dangerous products should only use them for their intended purposes. In these contexts, so-called "bilateral care accidents," imposing all liability on injurers is not generally efficient because in that case victims have little or no incentive to be careful. In contrast, the negligence rule creates incentives for both injurers and victims to invest in efficient accident prevention. ${ }^{15}$

The reason for this striking result can be seen as follows. As demonstrated above, the due care standard creates a strong incentive for injurers to meet the standard in order to avoid liability, which implies that any accident losses will remain on the victim. And since victims rationally anticipate that this will be the case, they have an incentive to invest in efficient accident prevention so as to minimize their expected losses. The negligence rule thus induces efficient prevention by both injurers and victims because it combines two methods for creating

\footnotetext{
${ }^{15}$ Brown (1973) was apparently the first to demonstrate this result. Also see Shavell (2004, pp. 182-193). Appendix 2 provides a simple proof.
} 
efficient incentives—namely, it sets a threshold level of care that allows the injurer to avoid liability by meeting the threshold (as shown above), and it simultaneously imposes full damages on the victim. ${ }^{16}$

The preceding argument has established the superiority of negligence over strict liability for minimizing accident costs. This suggests that if both rules exist in the population, selective litigation implies that cases involving negligence should come before the court less often than cases involving strict liability. As a result, negligence should become (or remain) the dominant legal rule, absent the existence of a judicial bias against it. This forms the basis for the persistence argument advanced above.

\subsection{Negligence and "Exaptation": Gould and Holmes}

As a final component of the argument, I wish relate the persistence of negligence law to an interesting phenomenon in biological evolution that concerns the survival of characteristics that have outlived their initial function, only to assume a new one. In standard Darwinian theory, the utility of a structure in an organism's struggle for survival is usually also the reason for the origin and continued existence of that structure. That is, the structure emerges and is shaped by natural selection to serve the current adaptive purpose. However, in discussing some of the difficulties with his theory in Chapter 6 of the 1872 edition of The Origin of Species, Darwin himself noted the possibility of a disconnect between the original function of a structure- - that is, the reason for its initial selection and survival—and its current usefulness: "In considering

\footnotetext{
${ }^{16}$ Negligence law often supplements the due standard for injurers with a corresponding standard for victims, referred to as contributory negligence. (See Davies v. Mann, 11 East 60 (K.B. 1809). Under contributory negligence, failure of victims to meet the due standard of care prevents them from recovering damages regardless of the injurer's care level. The logic of this rule is the same as that for the Hand test, and it similarly creates a powerful incentive for victims to invest in efficient accident prevention. In terms of efficiency, however, creation of a due standard for victims is redundant since, as we have just seen, the "simple" negligence rule which only establishes a due standard for injurers is adequate to create efficient bilateral incentives. Landes and Posner (1987, p. 76) offer an efficiency argument for contributory negligence.
} 
transitions of organs, it is so important to bear in mind the probability of conversion from one function to another" (Darwin, 1936 [1872] p. 137). Gould and Vrba (1982) proposed the term "exaptations" to describe such converted structures:

Vrba and I proposed that features co-opted for a current utility following an origin for a different function (or for no function at all) be called exaptations - that is, useful (or aptus) as a consequence of (ex) their form - in contrast to adaptations, or features directly crafted for their current utility (Gould, 2002, p. 1232, italics in original).

Once a form has been co-opted (or exapted) in this way, it generally undergoes further selective refinement in its new function, thus often obscuring or erasing the reason for its origin. Darwinians have used the notion of exaptation to explain, for example, how complex organs (like eyes) could have arisen by incremental stages, as required by natural selection. (See, for example, the lengthy discussion and examples provided by Gould (2002, Chapter 11).)

We have already noted the relevance of selection arguments for explaining the evolution of the common law. It is therefore not surprising that the concept of an exaptation can be found there as well. As Holmes (1963 [1881], p. 32) noted in his treatise on the common law,

$[\mathrm{I}] \mathrm{t}$ will be found that, when ancient rules maintain themselves, ... new reasons more fitted to the time have been found for them, and that they gradually receive a new content, and at last a new form, from the grounds to which they have been transplanted.

Holmes illustrates this principle with the claim that modern notions of civil and criminal liability for wrongful harms are rooted in the primitive notion of vengeance. Although retaliation and vengeance may have been functional ways of dealing with criminal acts in primitive society where public institutions did not exist to apprehend and punish wrongdoers, such a system would obviously not be efficient in modern society because of the high level of violence it entails. It has therefore been replaced by our current publicly-run criminal justice system. Still, vestiges of such primitive notions as proportional punishment (an eye for an eye) and liability for damages 
exist in modern legal systems, though they are now generally justified on compensation or deterrence grounds. (See, for example, Posner (1983, Chapter 8) and Adelstein (1981).)

The discussion in the preceding sections suggests that a similar argument can be applied to negligence law. In particular, I argued above that the concept of negligence was initially "selected" by judges because of its usefulness in pursuing their goal of subsidizing infant industries during the nineteenth century. Thus, one might characterize the initial emergence of negligence as having been due to "artificial" selection by judges. However, once the concept had outlived its usefulness for this purpose, "natural" selection took over and co-opted negligence for a different purpose—namely, minimization of accident costs. The continued persistence of negligence during this phase of evolution (and up to the present) can therefore be largely attributed to its efficiency properties, which were only coincidentally related to its initial value for subsidizing industry. In this sense, one can argue that negligence has survived as a legal example of exaptation.

\section{Conclusion}

Law and economics scholars have advanced the proposition that the common law, by which they mean the body of precedents that emanates from judicial decisions, evolves toward efficiency. Early theories centered on the behavior of judges based on the argument that they preferred efficient rules, but more sophisticated models emphasized the invisible hand nature of legal change. The argument usually runs as follows: because inefficient laws impose larger costs on individuals than efficient laws, they will be litigated more frequently, thereby allowing judges more opportunities to evaluate and (possibly) overturn them. Thus, as long as judges are not 
biased against efficiency, inefficient laws will tend to be replaced by efficient laws. This process is referred to as selective litigation

Recent models of legal change have sought to re-introduce judges into the process in order to evaluate the combined effects of judicial bias (artificial selection) and selective litigation (natural selection) on the evolution of the law. This paper used a simple Markov model to formalize the interaction of these two effects. The conclusions were then applied to the evolution of accident law during the nineteenth century. In particular, the paper argued that according to the conventional account, negligence first arose as the predominant rule for allocating accident costs because judges consciously sought to insulate businesses (especially railroads) from liability in an effort to promote economic development during the early stages of the industrial revolution. However, the persistence of negligence long after any reason for subsidization had expired can only be attributed to the selection effect, which favored negligence over competing rules because of its efficiency properties. This argument for the survival of negligence is similar to the concept of exaptation in biological evolution, whereby a characteristic outlives its initial function but is then co-opted for another one because of its adaptive value. 


\section{Appendix 1.}

This appendix shows the impact of precedent on the evolution of legal rules. Let $R$ be the probability that a judge follows precedent by upholding the existing legal rule, regardless of his or her personal preferences. Thus, $R=1$ means that the precedent is completely binding on judges and the law never evolves, whereas $R=0$ means that precedent is not binding at all and the law evolves according to the model in the text. In the intermediate case where $0<R<1$ (i.e., precedent is partially binding), the law will evolve more slowly than if $R=0$, but it turns out that the steady state equilibrium is unaffected. To show this, note that when precedent matters, equation (1), which shows the proportion of rule 1 after one period of litigation, becomes

$$
y_{1}=x_{1}\left(1-a_{1}\right)+x_{1} a_{1}\left[p_{12} R+\left(1-p_{12}\right)\right]+\left(1-x_{1}\right) a_{2} p_{21}(1-R) .
$$

Precedent enters this expression in two ways: first, it prevents some judges from replacing rule 1 with rule 2 , thereby increasing the frequency of rule 1 (second term on the right-hand side); and second, it prevents some judges from replacing rule 2 with rule 1 , thereby reducing the frequency of rule 1 (third term on the right-hand side). Note that if $R=0$, (A1) reduces to (1), while if $R=1$, $y_{1}=x_{1}$ (i.e., the law never changes). Generally, for any $R<1$, (A1) can be solved, as in the text, for the steady state frequency of rule 1 . The resulting expression turns out to be identical to that in (2); that is, $s_{1}$ is independent of $R$. This proves the claim in the text that precedent, as long as it is not strictly binding, has no effect on the distribution of legal rules. A larger $R$ will, however, slow the rate at which the law approaches the steady state.

\section{Appendix 2.}

This appendix proves the efficiency of the negligence rule in bilateral care accidents. Consider the following simple accident model, originally due to Brown (1973). Let

$p(x, y)=$ the probability of an accident;

$x=$ spending on precaution (care) by the injurer;

$y=$ spending on care by the victim;

$L=$ loss in the event of an accident. ${ }^{17}$

Assume that $p_{x}<0, p_{x x}>0, p_{y}<0$, and $p_{y y}>0$. Thus, care by both injurers and victims reduces accident risk, though at a decreasing rate. ${ }^{18}$ The socially optimal choices of $x$ and $y$ minimize expected accident costs, given by

$$
x+y+p(x, y) L
$$

The resulting first order conditions, which jointly determine $x^{*}$ and $y^{*}$, are

$$
\begin{aligned}
& 1+p_{x} L=0 \\
& 1+p_{y} L=0 .
\end{aligned}
$$

\footnotetext{
${ }^{17}$ I treat $L$ as fixed, but in a more general model, it would also depend on $x$ and $y$.

${ }^{18}$ It is also usually assumed that $p_{x y}>0$, reflecting the fact that care by injurers and victims is substitutable.
} 
Now consider the incentives of the injurer and victim under strict liability and under negligence. First under strict liability, the injurer is liable for the full amount of damages in the event of an accident, so he chooses $x$ to minimize $x+p(x, y) L$, taking $y$ as given. His reaction function, $x^{*}(y)$, thus solves (A3) for any $y$, implying that he chooses the efficient level of care conditional on $y$. As for the victim, because she is fully compensated for her losses, she will choose $y=0$. Thus, the Nash equilibrium is $(x *(0), 0)$, which is inefficient.

Now consider the negligence rule, where I assume (as is typical) that the due standard of care is set at the injurer's efficient level, $x^{*}$. To prove that the Nash equilibrium involves efficient care by both parties, assume initially that $y=y^{*}$. The injurer's best response is therefore $x^{*}$ since he thereby avoids liability, and $x^{*}<x^{*}+p\left(x^{*}, y^{*}\right) L \leq \min _{x<x^{*}} x+p\left(x, y^{*}\right) L$. (Obviously, the injurer would never choose $x>x^{*}$ in this case.) Now let $x=x^{*}$. Since the victim knows that the injurer avoids liability, her best response is to choose $y$ to minimize $y+p\left(x^{*}, y\right) L$, which yields $y^{*}\left(x^{*}\right)=y^{*}$. This proves that both the injurer and victim choose efficient care in a Nash equilibrium under negligence. 


\section{References}

Adelstein, R. (1981) "Institutional Function and Evolution in the Criminal Process," Northwestern Univ. Law Review 76: 1-99.

Brown, J. (1973) “Toward and Economic Theory of Liability,” Journal of Legal Studies 2: 323349.

Cooter, R. and L. Kornhauser (1980) "Can Litigation Improve the Law without the Help of Judges?” Journal of Legal Studies: 139-163.

Darwin, C. (1936 [1872]) The Origin of Species, New York: Modern Library.

Epstein, R. (1980) Modern Products Liability Law, Westport, CT: Quorum Books.

Gennaioli, N. and A. Shleifer (2007a) “The Evolution of Common Law," Journal of Political Economy 115: 43-68.

(2007b) "Overruling and Instability of Law," Journal of Comparative Economics35: 309-328.

Goodman, J. (1978) “An Economic Theory of the Evolution of the Common Law," Journal of Legal Studies 7: 393-406.

Gould, S. (2002) The Structure of Evolutionary Theory, Cambridge, MA: Belknap Press.

Gould, S. and S. Vrba (1982) "Exaptation-A Missing Term in the Science of Form," Paleobiology 3: 4-15.

Hadfield, G. (1992) "Bias in the Evolution of Legal Rules," Georgetown Law Journal 80: 583616.

Holmes, O. (1963 [1881]) The Common Law, Boston: Little, Brown and Co.

Horowitz, M. (1992a) The Transformation of American Law, 1780-1860, New York: Oxford Univ. Press.

(1992b) The Transformation of American Law, 1870-1960, New York: Oxford Univ. Press.

Keeton, W., D. Dobbs, R. Keeton, and D. Owen (1984) Prosser and Keeton on Torts, $5^{\text {th }}$ Ed., St. Paul, MN: West Publishing Co.

Landes, W. (1971) “An Economic Analysis of the Courts," Journal of Law and Economics 14: $535-567$ 
Landes, W. and R. Posner (1976) "Legal Precedent: A Theoretical and Empirical Analysis," Journal of Law and Economics 19: 249-307.

(1985) "A Positive Economic Theory of Products Liability," Journal of Legal Studies 14: 535-567.

(1987) The Economic Structure of Tort Law, Cambridge, MA: Harvard Univ.

Press.

Miceli, T. (2009) "Legal Change: Selective Litigation, Judicial Bias, and Precedent," Journal of Legal Studies 38: 157-168.

( 2010) "Legal Change and the Social Value of Lawsuits," International Review of Law and Economics 30: 203-208.

Miceli, T. and M. Cosgel (1994) "Reputation and Judicial Decision-making," Journal of Economic Behavior and Organization 23: 31-51.

Posner, R. (1972) “A Theory of Negligence,” Journal of Legal Studies 1: 29-96.

(1983) The Economics of Justice, Cambridge, MA: Harvard Univ. Press.

(2003) Economic Analysis of Law, $6^{\text {th }}$ Ed., New York: Aspen Law and Business.

Priest, G. (1977) "The Common Law Process and the Selection of Efficient Rules," Journal of Legal Studies 6: 65-82.

(1988) "Products Liability Law and the Accident Rate," in R. Litan and C. Winston (eds.) Litigation" Perspectives and Policy, Wahsington, DC: Brookings.

Rubin, P. (1977) “Why is the Common Law Efficient?” Journal of Legal Studies 6: 51-63.

Shavell, S. (2004) Foundations of Economic Analysis of Law, Cambridge, MA: Belknap Press.

Terrebonne, R. (1981) “A Strictly Evolutionary Model of Common Law," Journal of Legal Studies 10: 397-407.

Viscusi, W. K. (1991) Reforming Products Liability, Cambridge, MA: Harvard Univ. Press. 